\author{
MaPan : Jurnal Matematika dan Pembelajaran \\ p-ISSN: 2354-6883 ; e-ISSN: 2581-172X \\ Volume 7, No 2, December 2019 (167-180) \\ DOI: https://doi.org/10.24252/mapan.2019v7n2a1
}

\title{
ETNOMATEMATIKA PADA BANGUNAN UTAMA ASRAMA INGGRISAN BANYUWANGI SEBAGAI MEDIA PEMBELAJARAN
}

\author{
Agustin Faridatul Hasanah 1), Susanto 2), Dinawati Trapsilasiwi3) \\ 1,2,3Program Studi Pendidikan Matematika, Universitas Jember \\ 1,2,3Jl. Kalimantan 37, Jember 68121 \\ E-mail: afnah108@gmail.com ${ }^{1)}$, susantouj@gmail.com ${ }^{2}$, $\underline{\text { dinawati.fkip@unej.ac.id }}^{3}$ )
}

Submitted: 12-09-2019, Revised: 24-11-2019, Accepted: 26-11-2019

\begin{abstract}
Abstrak:
Matematika merupakan aktivitas manusia dan bagian dari budaya. Hubungan antara budaya dan matematika dikenal sebagai etnomatematika. Pengintegrasian budaya dalam pembelajaran matematika dapat membantu siswa dalam memahami materi matematika yang abstrak. Penelitian ini bertujuan mendeskripsikan etnomatematika pada bangunan utama Asrama Inggrisan Banyuwangi yang merupakan bangunan bekas peninggalan kolonial dan menyimpan banyak kisah sejarah dari Inggris, Belanda hingga Jepang, serta memanfaatkan hasil penelitiannya menjadi question cards berbasis etnomatematika. Jenis penelitian yang digunakan dalam penelitian ini adalah penelitian kualitatif. Metode pengumpulan data pada penelitian ini, yaitu observasi, wawancara, dan dokumentasi. Hasil penelitian menunjukkan bahwa arsitektur bangunan utama Asrama Inggrisan memiliki bentuk-bentuk yang dianggap representasi dari konsep geometri, yaitu garis, sudut, bangun datar, bangun ruang sisi datar, kesebangunan dan kekongruenan, simetri, dan transformasi geometri.
\end{abstract}

Kata Kunci: Asrama Inggrisan Banyuwangi, Etnomatematika, Question Cards

\section{ETHNOMATHEMATICS ON THE MAIN BUILDING OF ASRAMA INGGRISAN BANYUWANGI AS LEARNING MEDIA}

\begin{abstract}
:
Mathematics relates to the human's activity and part of the culture. The relationship between culture and mathematics is known as ethnomathematics. Integrating culture in mathematics learning can help the students to understand abstract mathematical material. This research aims to describe the ethnomathematics on the main building of Inggrisan dormitory in Banyuwangi which is a former colonial heritage building and saves many historical stories from England, Netherlands, and Japan. The research used was qualitative research. Data collection procedures in this study were observation, interviews, and documentation. The results showed that the architecture of the main building of Inggrisan dormitory in Banyuwangi had forms which were considered to be representations of geometrical concepts, including lines, angles, flat shapes, flat side spaces, congruence and concordance, symmetry, and geometric transformations which produced ethnomathematics-based question cards for mathematics learning.
\end{abstract}

Keywords: Asrama Inggrisan Banyuwangi, Ethnomathematics, Question Cards 
How to Cite: Hasanah, A. F., Susanto, \& Trapsilasiwi, D. (2019). Etnomatematika pada bangunan utama Asrama Inggrisan Banyuwangi sebagai media pembelajaran. MaPan: Jurnal Matematika dan Pembelajaran, 7(1), 167-180.

\section{PENDAHULUAN}

$\mathrm{M}$ atematika merupakan aktivitas manusia dan bagian dari budaya. Peran matematika hampir mencakup seluruh aspek kegiatan manusia yang dapat diuraikan menjadi suatu model matematika. Hal ini sesuai dengan pendapat Sujadi \& Wiyoto (2011) mengatakan bahwa matematika merupakan aktivitas insani (human activities) yang dapat dikaitkan dengan realitas. Namun, sampai sekarang ketertarikan siswa terhadap matematika masih kurang karena tidak sedikit siswa yang menganggap bahwa matematika itu sulit dan menakutkan. Matematika sulit dipahami oleh siswa karena ada dua skema yang menjadi alasan, yaitu skema yang diperoleh di lingkungan dan skema yang diperoleh di sekolah (Sirate, 2012). Di samping itu, kebermaknaan pembelajaran matematika di sekolah saat ini sangat diperhatikan. Kebermaknaan diperoleh karena materi matematika dihubungkan dengan pengalaman siswa, kehidupan sosial, bahkan menyentuh ranah seni dan budaya setempat (Richardo, 2016). Suatu strategi penciptaan lingkungan belajar dan perancangan pengalaman belajar yang mengintegrasikan nilai-nilai budaya di dalamnya disebut pembelajaran berbasis budaya. Pembelajaran berbasis budaya akan memberikan pemahaman secara kontekstual kepada siswa berdasarkan pengalamannya sebagai bagian dari masyarakat budaya. Oleh karena itu, pembelajaran dengan pendekatan budaya perlu digunakan untuk menciptakan pembelajaran matematika yang bermakna dan juga menyenangkan.

Budaya adalah sistem nilai dan ide yang dihayati oleh sekelompok manusia di suatu lingkungan hidup tertentu dan di suatu kurun waktu tertentu (Putri, 2017). Hubungan antara budaya dan matematika dikenal sebagai etnomatematika. Etnomatematika merupakan suatu cara yang digunakan untuk mempelajari matematika dengan melibatkan aktivitas atau budaya daerah sekitar sehingga memudahkan seseorang untuk memahami (Sarwoedi, Marinka, Febriani, \& Wirne, 2018). Jadi, etnomatematika merupakan matematika yang dipraktekkan oleh suatu kelompok budaya namun dengan cara tertentu dalam aktivitas sehari-hari seperti berhitung, mengukur, merancang bangunan atau alat, membuat pola, dan sebagainya. 
Sejauh ini, budaya yang telah diekplorasi berkaitan dengan sistem bilangan, game (permainan), geometri, bentuk, ruang, pola atau susunan, simetris, seni dan arsitektur, serta artefak (Gerdes, 2007; Zaslavsky, 1994). Pengintegrasian budaya dalam pembelajaran matematika dapat membantu siswa dalam memahami materi matematika yang abstrak (Astutiningtyas, Wulandari, \& Farahsanti, 2017). Hal ini dikarenakan konsep dan pengetahuan yang terkonstruksi oleh siswa benar-benar nyata berdasarkan pengalaman siswa sendiri di lingkungannya, sehingga pembelajaran matematika bagi setiap siswa seharusnya dikaitkan dengan budaya dan lingkungannya (Rakhmawati, 2016; Wahyudi, Suyitno, \& Waluya, 2018). Dari berbagai pendapat tersebut, maka sekolah perlu mengajarkan matematika di sekolah dan mengaitkannya dengan masalah yang ada dalam kehidupan sehari-hari, khususnya yang berkaitan dengan budaya agar siswa mudah memahaminya.

Berdasarkan uraian sebelumnya, penggunaan etnomatematika dalam pembelajaran matematika membutuhkan suatu media yang berada di lingkungan siswa demi tercapainya pembelajaran matematika yang bermakna. Salah satu media tersebut adalah melalui Asrama Inggrisan yang terletak di Banyuwangi. Asrama Inggrisan merupakan bangunan bekas peninggalan kolonial yang saat ini digunakan sebagai Asrama KODIM 0825 Banyuwangi. Suhailik mengatakan bahwa arsitektur bangunan ini mengadopsi arsitektur lokal, yaitu gaya arsitektur rumah panggung khas orang Bugis yang tinggal di pesisir Kota Banyuwangi (Albab, 2018). Ciri khas yang paling menonjol pada Asrama Inggrisan adalah ventilasi dengan bentuk empat mahkota bunga dan keberadaan kolong bangunan (Risdyaningsih, Antariksa, \& Suryasari, 2015).

Penelitian ini bertujuan untuk mendeskripsikan etnomatematika yang terdapat pada bangunan utama Asrama Inggrisan Banyuwangi terkait materi geometri. Selain itu, hasil dari penelitian ini akan dibuat dalam bentuk question cards, sehingga dapat dimanfaatkan sebagai media pembelajaran di sekolah, khususnya sekolah-sekolah menengah pertama di sekitar Asrama Inggrisan Banyuwangi. Media question cards adalah media pembelajaran berbentuk kartu dengan gambar yang menarik dan berisi pertanyaan atau masalah terkait etnomatematika yang terdapat pada Asrama Inggrisan. Media tersebut dibuat dengan mengacu pada kurikulum 2013 revisi terbaru dan lebih menekankan pada pemikiran kritis siswa dalam memecahkan pertanyaan sesuai dengan gambar yang ada dalam kartu pertanyaan. 


\section{METODE PENELITIAN}

Jenis penelitian yang digunakan dalam penelitian ini adalah penelitian kualitatif. Daerah penelitian ini, yaitu di Asrama Inggrisan yang terletak di kota Banyuwangi, tepatnya di Jalan Diponegoro no. 01, Kelurahan Kepatihan, Banyuwangi. Metode pengumpulan data pada penelitian ini, yaitu observasi, wawancara, dan dokumentasi. Observasi dilakukan oleh dua orang observer, wawancara dilakukan kepada budayawan dan arkeolog, kemudian dokumentasi dilakukan dengan meninjau naskah usulan pemeringkatan "Rumah Inggrisan sebagai Cagar Budaya Kabupaten Banyuwangi" dan artikel terkait. Data yang telah diperoleh mengenai etnomatematika pada bangunan utama Asrama Inggrisan Banyuwangi selanjutnya direduksi, dipaparkan dalam bentuk deskripsi, kemudian diambil kesimpulan. Setelah itu, dibuat question card berbasis etnomatematika yang ditemukan pada bangunan tersebut.

\section{HASIL PENELITIAN DAN PEMBAHASAN}

Asrama Inggrisan menjadi salah satu bukti sejarah adanya hubungan kota Banyuwangi dengan negara Inggris, Belanda, dan Jepang pada masa penjajahan. Berdasarkan tinjauan naskah usulan pemeringkatan Rumah Inggrisan sebagai Cagar Budaya Kabupaten Banyuwangi, bangunan ini dibangun pada tahun 1811 oleh Letnan Kolonel Meycin S.Y yang berkebangsaan Inggris dan menikah dengan wanita Belanda. Pada halaman depan Asrama Inggrisan terdapat lempengan beton cor yang bertuliskan Burn Brothers, Rotunda Works, 3 Blackfriars Road, London SE. Tulisan ini membuktikan bahwa bangunan ini dulu pernah digunakan sebagai stasiun kabel telegraf bawah laut yang menjadi titik penghubung komunikasi antara pihak Inggris dengan Australia. Terdapat beberapa bangunan di dalam Asrama Inggrisan, namun penelitian ini fokus pada bangunan utama yang ukurannya paling besar dibanding bangunan lain. Bangunan utama yang sebelumnya difungsikan sebagai barak prajurit memiliki bangunan pendukung di bagian belakangnya. Berdasarkan hasil penelitian menunjukkan bahwa terdapat aktivitas mendesain dan mengukur pada Asrama Iggrisan Banyuwangi. Hal ini ditunjukkan dengan bagian bangunan utama asrama yang memiliki bentuk unik dan proporsi yang seimbang. Bangunan utama Asrama Inggrisan Banyuwangi dapat dilihat pada gambar 1, sedangkan ilustrasi fasad (tampak depan) bangunan utama dapat dilihat pada gambar 2 berikut. 


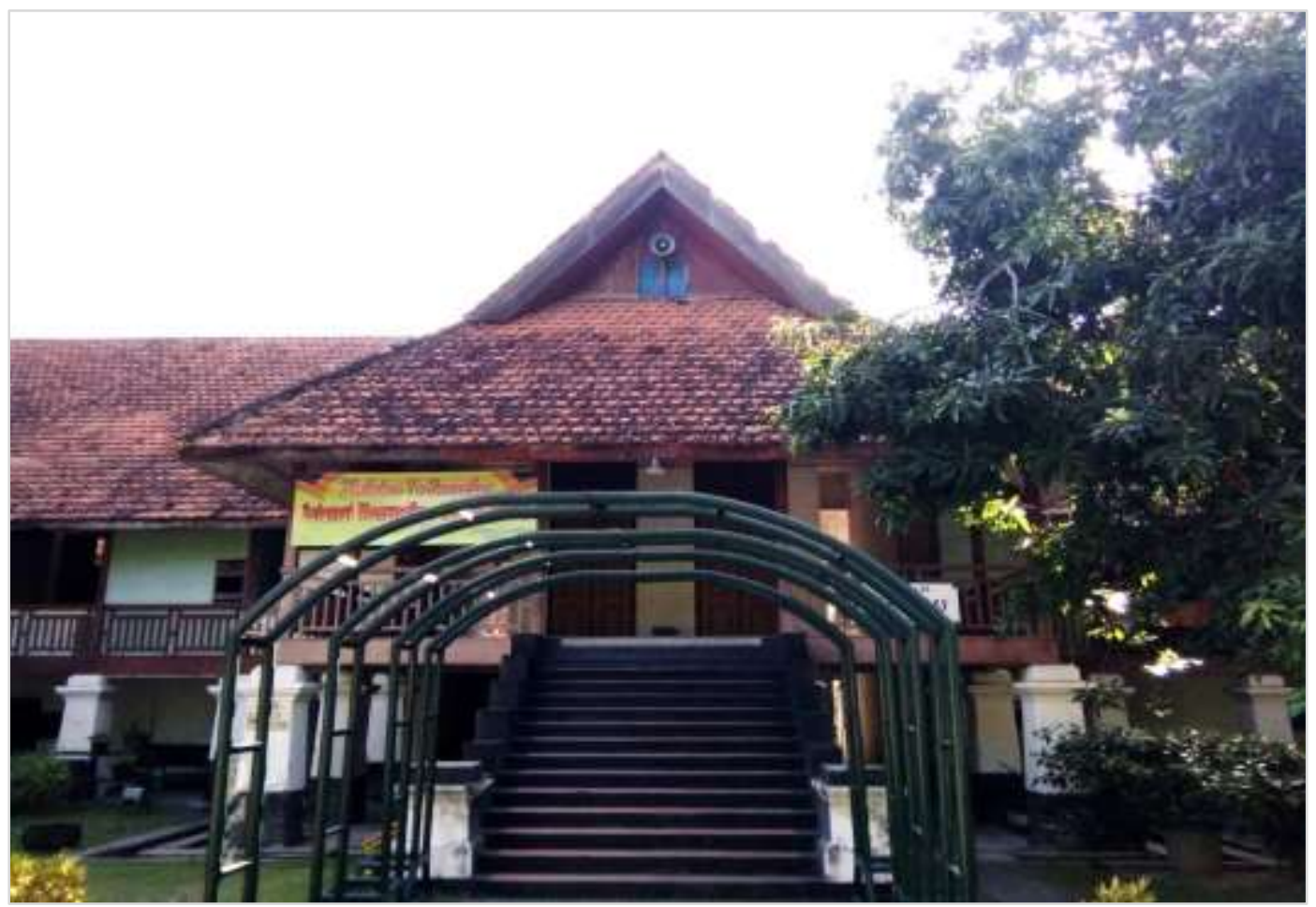

Gambar 1. Bangunan Utama Asrama Inggrisan Banyuwangi

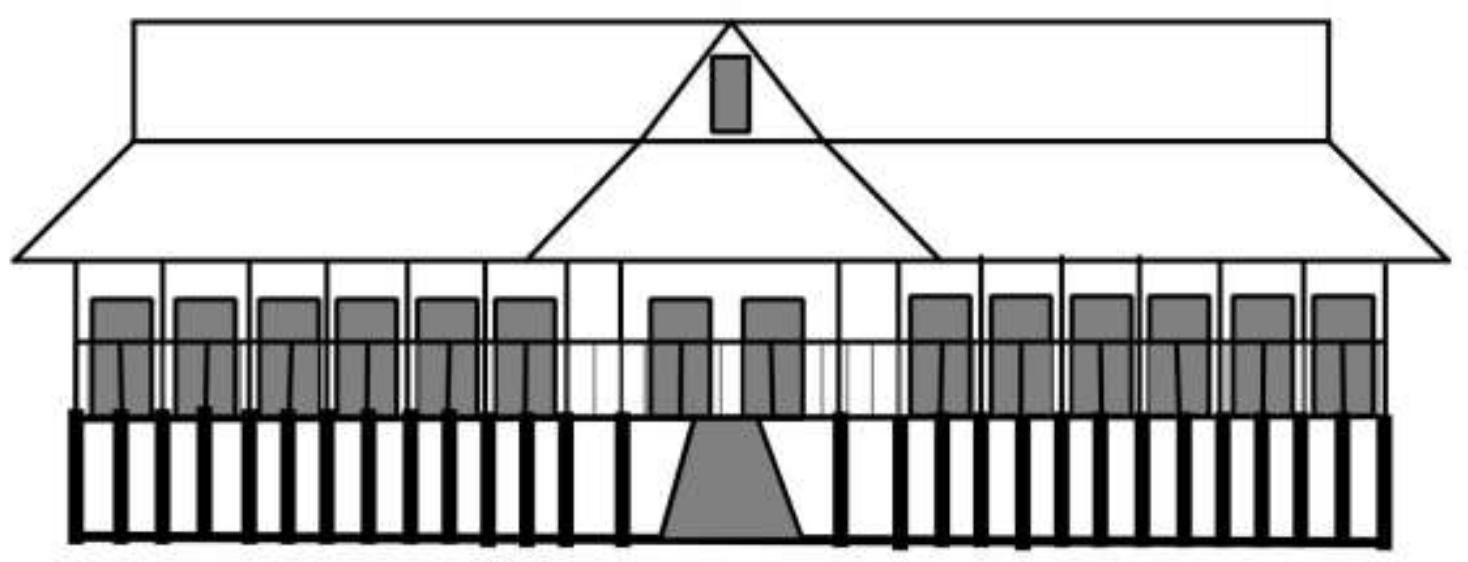

Gambar 2. Ilustrasi Tampak Depan Bangunan Utama 
Etnomatematika yang terdapat pada bangunan utama Asrama Inggrisan dirangkum dalam tabel berikut.

Tabel 1. Etnomatematika pada Asrama Inggrisan Banyuwangi

\begin{tabular}{|c|c|c|c|}
\hline Komponen & $\begin{array}{c}\text { Sub } \\
\text { Komponen }\end{array}$ & $\begin{array}{c}\text { Konsep Geometri yang } \\
\text { Ditemukan }\end{array}$ & Indikator \\
\hline \multirow[t]{8}{*}{$\begin{array}{l}\text { Bangunan } \\
\text { Utama }\end{array}$} & Atap & $\begin{array}{l}\text { Segitiga, Trapesium, } \\
\text { Prisma segitiga sama } \\
\text { kaki, Limas } \\
\text { terpancung, Sudut } \\
\text { lancip, dan } \\
\text { Kekongruenan }\end{array}$ & \multirow{12}{*}{$\begin{array}{l}\text { Garis, Sudut, } \\
\text { Bangun Datar, } \\
\text { Bangun Ruang } \\
\text { Sisi Datar, } \\
\text { Kesebangunan, } \\
\text { Simetri, dan } \\
\text { Transformasi } \\
\text { Geometri }\end{array}$} \\
\hline & Pintu & $\begin{array}{l}\text { Persegi panjang, } \\
\text { Refleksi, } \\
\text { Kekongruenan }\end{array}$ & \\
\hline & Jendela & $\begin{array}{l}\text { Persegi panjang, } \\
\text { Kekongruenan, dan } \\
\text { Sudut siku-siku }\end{array}$ & \\
\hline & $\begin{array}{l}\text { Pagar } \\
\text { pembatas } \\
\text { balkon }\end{array}$ & $\begin{array}{l}\text { Garis sejajar dan tegak } \\
\text { lurus }\end{array}$ & \\
\hline & Lantai & Persegi panjang & \\
\hline & $\begin{array}{l}\text { Kolom } \\
\text { penopang }\end{array}$ & $\begin{array}{l}\text { Balok, Limas } \\
\text { Terpancung, dan } \\
\text { Kekongruenan }\end{array}$ & \\
\hline & $\begin{array}{l}\text { Kolong } \\
\text { bangunan }\end{array}$ & $\begin{array}{l}\text { Persegi, Lingkaran, dan } \\
\text { Kekongruenan }\end{array}$ & \\
\hline & Tangga & $\begin{array}{l}\text { Persegi panjang, } \\
\text { Trapesium, Balok, dan } \\
\text { Refleksi }\end{array}$ & \\
\hline \multirow[t]{3}{*}{$\begin{array}{l}\text { Bangunan } \\
\text { pendukung }\end{array}$} & Atap & $\begin{array}{l}\text { Persegi panjang, } \\
\text { Segitiga, dan } \\
\text { Kesebangunan }\end{array}$ & \\
\hline & Ventilasi & $\begin{array}{l}\text { Persegi, Lingkaran, } \\
\text { Trapesium, Simetri, } \\
\text { Refleksi }\end{array}$ & \\
\hline & Pintu & $\begin{array}{l}\text { Persegi panjang, } \\
\text { Lingkaran }\end{array}$ & \\
\hline Taman & & $\begin{array}{l}\text { Persegi panjang, } \\
\text { Persegi, Simetri, } \\
\text { Refleksi }\end{array}$ & \\
\hline
\end{tabular}


Berdasarkan tabel 1, dapat diketahui bahwa bentuk pada bagian-bagian bangunan utama Asrama Inggrisan dianggap merupakan representasi dari konsep-konsep geometri, yaitu garis, sudut, bangun datar, bangun ruang sisi datar, kesebangunan dan kekongruenan, simetri, dan transformasi geometri.

Alexander \& Koeberlein (2011) mendeskripsikan garis sebagai kumpulan/himpunan titik-titik yang banyaknya tak hingga. Pada pembuatan pagar balkon yang terdapat di bangunan utama ditemukan konsep garis. Prinsip kesejajaran digunakan pada balok kayu yang dipasang secara vertikal ataupun horizontal karena jika balok kayu tersebut diperpanjang maka tidak akan saling berpotongan. Prinsip ketegaklurusan digunakan pada sambungan antara balok kayu yang dipasang horizontal dan balok kayu yang dipasang vertikal atau sebaliknya karena jika balok kayu diperpanjang akan saling berpotongan membentuk sudut yang kongruen. Prinsip kesejajaran dan ketegaklurusan yang ditemukan pada pagar balkon dapat dilihat pada gambar 3 berikut.

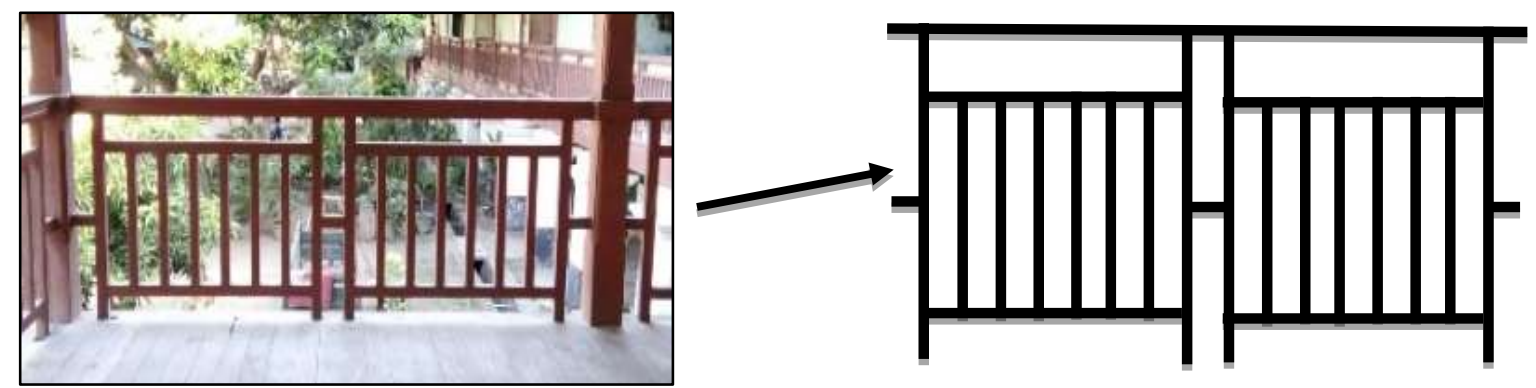

Gambar 3. Ilustrasi Bentuk Pagar Balkon

Selanjutnya, yang dimaksud sudut adalah penyatuan atau gabungan dua sinar yang memiliki titik pangkal yang sama (Alexander \& Koeberlein, 2011). Jenis-jenis sudut dibedakan berdasarkan ukuran yang terbentuk antara dua sinar tersebut. Pada jendela dinding yang tersusun atas 5 buah kaca berbentuk persegi panjang ditemukan konsep sudut. Masing-masing kaca akan terbuka dan membentuk sudut siku-siku apabila tuas pembuka ditarik secara maksimal, sedangkan pada atap bangunan utama ditemukan penggunaan sudut lancip. Konsep sudut tersebut diperlihatkan pada gambar 4 berikut. 


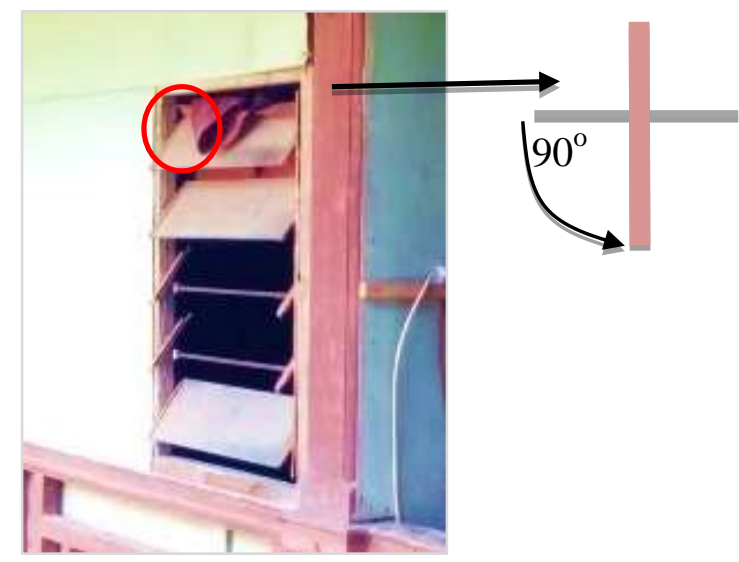

Gambar 4. Konsep Sudut pada Jendela

Poligon merupakan bangun datar tertutup yang dibatasi oleh ruas-ruas garis lurus sebagai sisinya (Rich \& Thomas, 2009). Hampir pada setiap bagian bangunan utama Asrama Inggrisan ditemukan konsep bangun datar. Bangun datar yang digunakan adalah segitiga, trapesium, persegi panjang, persegi, dan lingkaran. Bagian depan atap bangunan utama tampak berbentuk persegi panjang, segitiga, dan trapesium. Bagian depan atap bangunan pendukung tampak berbentuk persegi panjang bertingkat, sedangkan bagian sampingnya menyerupai bangun segitiga bertingkat.

(a)

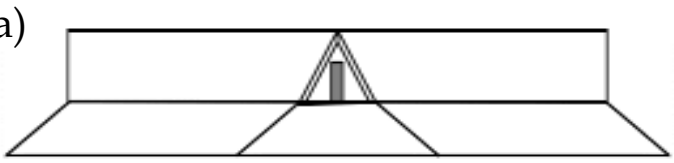

(b)

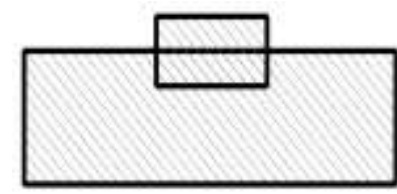

Gambar 5. Ilustrasi Bentuk Atap Bangunan Utama (a) dan Bangunan Pendukung (b)

Segitiga yang digunakan adalah segitiga sama kaki. Menurut filosofi Jawa, bentuk segitiga mengajarkan kita untuk tidak melupakan "hablumminallah". Selain itu, persegi panjang juga ditemukan pada bagian bangunan utama asrama yang lain, yaitu pintu, jendela, lantai, kolom pendukung tangga, kolong bangunan, dan taman.

Bagian tengah ventilasi bunga dengan empat mahkota dan lantai pot bunga yang terdapat di taman tampak berbentuk persegi. Selanjutnya, pada ventilasi kamar mandi ditemukan bangun trapesium. Ventilasi dengan bentuk seperti ini memiliki dua fungsi, yaitu sebagai ruang pertukaran udara dan tempat penerangan kamar mandi. Jadi, dua kamar mandi hanya memerlukan 
satu penerangan. Kemudian pada ventilasi kamar mandi juga ditemukan bentuk lingkaran. Selain lingkaran, terdapat juga bentuk yang merupakan bagian dari lingkaran itu sendiri, yaitu setengah lingkaran dan tembereng lingkaran. Setengah lingkaran digunakan oleh unsur kelopak pada ventilasi bunga dengan besi penyilang, sedangkan tembereng lingkaran digunakan oleh unsur kelopak pada ventilasi bunga tanpa besi penyilang dan bingkai yang menambah nilai seni pada pintu gudang.

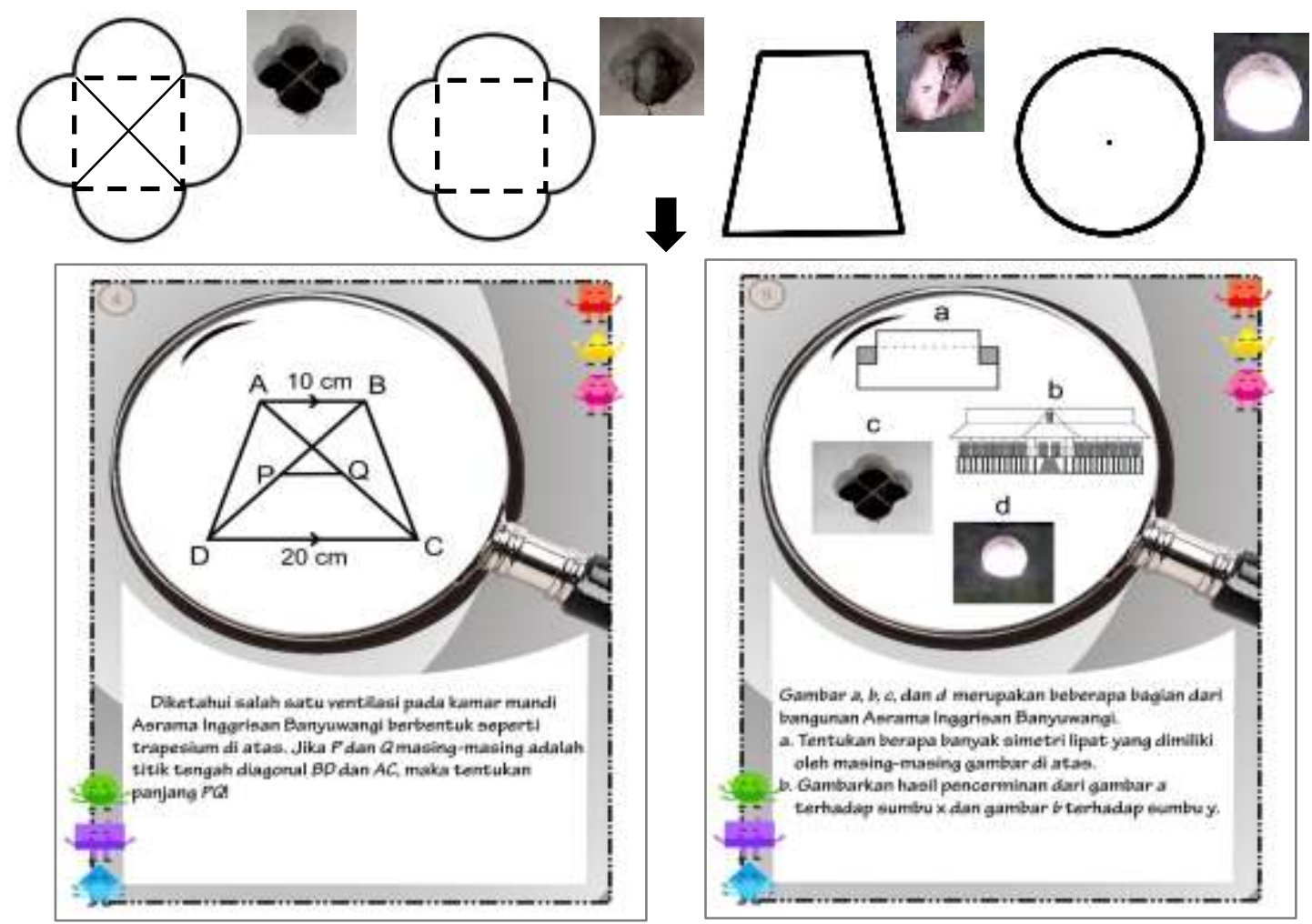

Gambar 6. Ilustrasi Bentuk Ventilasi serta Pemanfaatannya menjadi Question Cards

Menurut Rich \& Thomas (2009), polihedron adalah padatan atau ruang yang hanya dibatasi oleh bidang datar. Konsep bangun ruang sisi datar yang terdapat pada bangunan Asrama Inggrisan, antara lain balok, prisma segitiga, dan limas terpancung. Pada tangga dan kolom penopang terdapat padatan yang menyerupai balok. Bentuk limas terpancung dapat ditemukan pada atap bangunan utama dan juga kolom penopang. Jadi, kolom penopang terbentuk dari dari gabungan balok dan limas terpancung yang disusun secara teratur hingga memiliki nilai keindahan. 

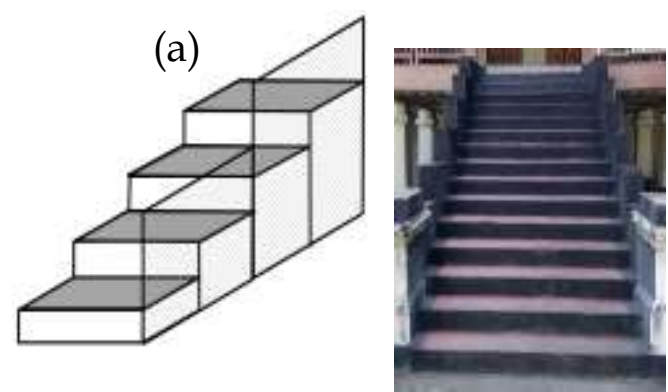

(b)

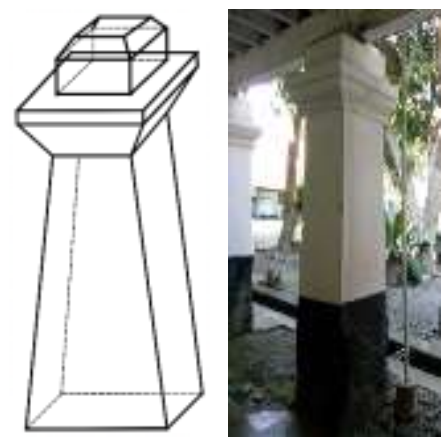

Gambar 7. Ilustrasi Bentuk Tangga (a) dan Kolom Penopang (b)

Selain konsep bangun datar, pada atap bangunan utama juga ditemukan bentuk prisma segitiga dan bentuk tersebut akan tampak apabila melihat atap secara keseluruhan. Prisma segitiga yang digunakan adalah prisma segitiga sama kaki. Berdasarkan penjelasan tersebut, dapat diketahui bahwa sebenarnya bentuk atap bangunan utama merupakan gabungan dari prisma segitiga sama kaki dan limas terpancung. Atap dengan arsitektur seperti ini merupakan hasil perpaduan antara budaya Eropa dan budaya lokal dan sepintas terlihat seperti atap berbentuk Joglo Limasan.
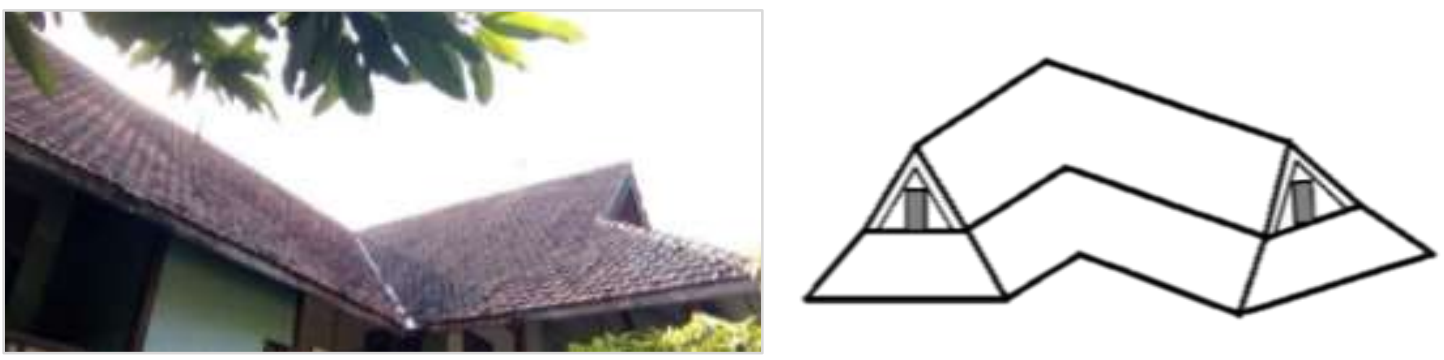

Gambar 8. Ilustrasi Bentuk Atap Bangunan Utama Tampak Keseluruhan

Sementara itu, kekongruenan dan kesebangunan menekankan pada bentuk dan ukuran dari dua buah bangun datar atau lebih. Kekongruenan adalah kesamaan besar sudut dan panjang sisi antara dua bangun datar atau lebih, sedangkan kesebangunan adalah kesamaaan besar sudut dan perbandingan panjang sisi antara dua bangun datar atau lebih. Pada bangunan utama khususnya atap, pintu, kaca penyusun jendela, bukaan lengkung pada kolong, dan sisi-sisi yang bersesuaian antara kolom penopang yang satu dengan yang lainnya ditemukan konsep kekongruenan. Terdapat empat bukaan lengkung yang masih terlihat pada kolong dan semuanya memiliki bentuk dan ukuran yang sama. Konsep kekongurenan pada pintu 
bangunan utama serta pemanfaatannya menjadi question cards dapat dilihat pada gambar 9 .
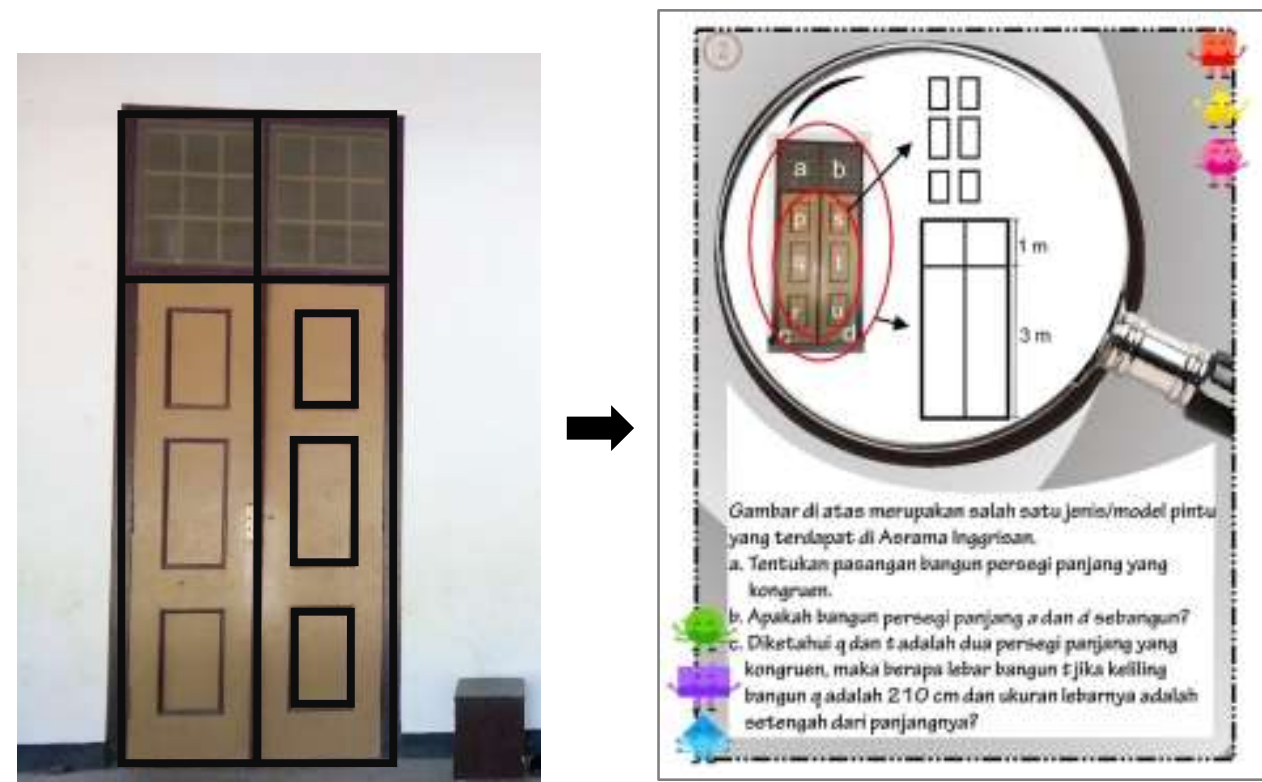

Gambar 9. Ilustrasi Bentuk Pintu Bangunan Utama serta Pemanfaatannya menjadi Question Cards

Mengenai konsep kesebangunan, bagian bangunan utama Asrama Inggrisan yang menunjukkan adanya konsep tersebut adalah atap bangunan pendukung yang menggunakan atap pelana bertumpuk untuk membantu sirkulasi udara. Bagian samping atap terdiri dari dua buah segitiga yang tersusun semakin ke atas semakin mengecil bentuknya, dengan perbandingan ukuran yang sama. Gustafson \& Frisk (1991) mengungkapkan bahwa segitigasegitiga itu dapat dikatakan sebangun jika panjang ketiga sisi pada suatu segitiga sebanding dengan panjang ketiga sisi pada segitiga yang lain. Kesebangunan tersebut dapat dilihat pada gambar 10.

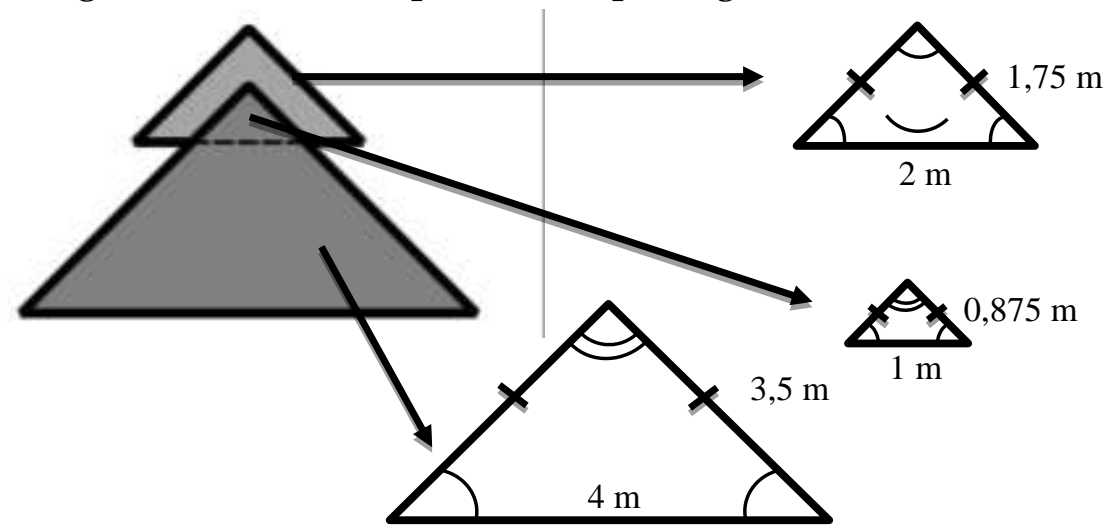

Gambar. 10 Kesebangunan pada Atap Bangunan Pendukung 
Simetri berarti setiap titik yang berada di sebelah kiri garis simetri selalu berpasangan atau berkorespondensi pada titik di sebelah kanan garis simetri (Alexander \& Koeberlein, 2011). Transformasi merupakan suatu pemetaan himpunan titik pada suatu bidang ke himpunan titik lain pada bidang yang sama. Transformasi yang ditemukan pada bangunan Asrama Inggrisan adalah refleksi. Pada ventilasi gudang yang berbentuk bunga dengan empat mahkota, pintu bangunan utama, kolom pendukung tangga, taman, dan tampilan bangunan baik dari depan maupun belakang terdapat konsep simetri dan refleksi. Bagian bangunan tersebut memiliki garis bagi yang tegak lurus dengan suatu ruas garis sehingga bagian kanan dan kiri atau bagian atas dan bawahnya memiliki ukuran yang sama dan tampak seperti dicerminkan.

Etnomatematika pada bangunan utama Asrama Inggrisan yang telah dipaparkan di atas dan hasilnya sebagai question cards dimaksudkan untuk memberikan inspirasi kepada guru dan siswa sehingga dapat menciptakan pembelajaran matematika yang bermakna dan menyenangkan. Berdasarkan penelitian-penelitian etnomatematika sebelumnya, seperti yang dilakukan oleh Fitriani, Somakin, \& Hartono (2018) dan Sroyer, Nainggolan, \& Hutabarat (2018), persamaan yang dimiliki penelitian ini dengan penelitianpenelitian tersebut adalah sama-sama mengidentifikasi konsep geometri yang mencakup bangun datar, bangun ruang, kesebangunan, kekongruenan, dan transformasi geometri. Namun, yang membedakan penelitian ini adalah penambahan konsep geometri yang akan diidentifikasi, yaitu konsep sudut dan adanya media pembelajaran berbentuk question cards yang berkaitan dengan etnomatematika pada bangunan Asrama Inggrisan Banyuwangi sebagai produk hasil penelitian.

\section{SIMPULAN}

Berdasarkan hasil penelitian, dapat diketahui bahwa bagian-bagian bangunan utama Asrama Inggrisan memiliki bentuk yang dianggap representasi dari konsep geometri, yaitu garis, sudut, bangun datar, bangun ruang sisi datar, kesebangunan dan kekongruenan, simetri, dan transformasi geometri. Pada pembuatan pagar balkon ditemukan prinsip kesejajaran dan ketegaklurusan. Pada bukaan kaca jendela dan atap bangunan utama ditemukan konsep sudut siku-siku dan lancip. Selanjutnya bagian depan atap bangunan utama yang tampak berbentuk segitiga, trapesium, dan persegi panjang. Kolom penopang yang merupakan keunikan lain pada bangunan 
Asrama Inggrisan tersusun atas padatan yang menyerupai balok dan limas terpancung. Pada atap bangunan utama, pintu, kaca penyusun jendela, bukaan lengkung pada kolong bangunan, dan sisi-sisi yang bersesuaian antara kolom penopang yang satu dengan yang lainnya ditemukan konsep kekongruenan. Kemudian pada bagian samping atap bangunan pendukung menunjukkan adanya konsep kesebangunan. Selain itu, pada ventilasi gudang yang berbentuk bunga dengan empat mahkota, pintu bangunan utama, kolom pendukung tangga, taman, dan tampilan bangunan baik dari depan maupun belakang ditemukan konsep simetri dan refleksi. Dari etnomatematika yang telah diperoleh dari penelitian ini, maka dibuat question cards dengan pokok bahasan materi kesebangunan dan kekongruenan dan pembuatannya berpedoman pada kurikulum 2013 revisi terbaru.

\section{DAFTAR PUSTAKA}

Albab, M. U. (2018). Kisah Asrama Inggrisan Banyuwangi dan pusat jaringan telegraf. Retrieved from https://m.merdeka.com/banyuwangi/infobanyuwangi/kisah-asrama-inggrisan-di-banyuwangi-dan-pusat-jaring an-telegraf-1802267.html.

Alexander, D. C., \& Koeberlein, G. M. (2011). Elementary geometry for college students. Canada: Brooks/Cole, Cengange Learning.

Astutiningtyas, E. L., Wulandari, A. A., \& Farahsanti, I. (2017). Etnomatematika dan pemecahan masalah kombinatorik. Jurnal Math Educator Nusantara, 3(2), 111-118. https:/ / doi.org/doi.org/10.29407/jm en.v3i2.907.

Fitriani, S., Somakim, \& Hartono, Y. (2018). Eksplorasi etnomatematika pada budaya masyarakat Jambi Kota Seberang. Journal of Medives : Journal of Mathematics Education IKIP Veteran Semarang, 2(2), 145-149. https:// doi.org/doi.org/10.31331/medivesveteran.v2i2.565.

Gerdes, P. (2007). Lunda geometry: Design, polyominoes, patterns, symmetries. Morrisville: Lulu Enterprises.

Gustafson, R. D., \& Frisk, P. D. (1991). Elementary geometry (3rd ed.). New York: John Wiley and Sons.

Putri, L. I. (2017). Eksplorasi etnomatematika kesenian rebana sebagai sumber belajar matematika pada jenjang MI. Jurnal Ilmiah "PENDIDIKAN DASAR," 4(1), 21-31. https://doi.org/dx.doi.org/10.30659/ pendas.4.1. $\% 25 \mathrm{p}$.

Rakhmawati, R. (2016). Aktivitas matematika berbasis budaya pada masyarakat Lampung. Al Jabar: Jurnal Pendidikan Matematika, 7(2), 221230. https://doi.org/doi.org/10.24042/ajpm.v7i2.37. 
Rich, B., \& Thomas, C. (2009). Schaum's outline: Geometry (4th ed.). New York: Mc Graw Hill.

Richardo, R. (2016). Peran ethnomatematika dalam penerapan pembelajaran matematika. Literasi, 7(2), 118-125. https:/ / doi.org/dx.doi.org/10.21927 /literasi.2016.7(2).118-125.

Risdyaningsih, A., Antariksa, \& Suryasari, N. (2015). Karakter visual bangunan utama kompleks Asrama Inggrisan kota Banyuwangi. Jurnal Mahasiswa Jurusan Arsitektur, 3(1). Retrieved from http://arsitektur.studentjournal. ub.ac.id/index.php/jma/article/view/84/84.

Sarwoedi, S., Marinka, D. O., Febriani, P., \& Wirne, I. N. (2018). Efektifitas etnomatematika dalam meningkatkan kemampuan pemahaman matematika siswa. Jurnal Pendidikan Matematika Raflesia, 3(2), 171-176. Retrieved from https:/ / ejournal.unib.ac.id/index.php/jpmr/article/ download/7521/3733.

Sirate, F. S. (2012). Implementasi etnomatematika dalam pembelajaran matematika pada jenjang pendidikan sekolah dasar. Lentera Pendidikan: Jurnal Ilmu Tarbiyah dan Keguruan, 15(1), 41-54. https:// doi.org/doi.org/10.24252/lp.2012v15n1a4

Sroyer, A. M., Nainggolan, J., \& Hutabarat, I. M. (2018). Exploration of ethnomathematics of house and traditional music tools Biak-Papua cultural. Formatif: Jurnal Ilmiah Pendidikan MIPA, 8(3), 175-184. https:/ / doi.org/dx.doi.org/10.30998/formatif.v8i3.2751

Sujadi, I., \& Wiyoto, J. (2011). Pemanfaatan matematika rekreasi dalam pembelajaran matematika di SD. Yogyakarta: PPPPTK Matematika.

Wahyudi, Suyitno, H., \& Waluya, S. B. (2018). Dampak perubahan paradigma baru matematika terhadap kurikulum dan pembelajaran matematika di Indonesia. Jurnal Ilmiah Kependidikan, 1(1), 38-47. https:/ / doi.org/10.241 76/jino.vlil.2315.

Zaslavsky, C. (1994). "Africa counts" and ethnomathematics. For the Learning of Mathematics, 14(2), 3-8. Retrieved from https:/ / www.jstor.org/stable /40248107?seq=1. 